\title{
EXPERIMENTAL DETERMINATION OF WORM GEARING EFFICIENCY
}

UDC: $62-233.3$

Original scientific paper

https://doi.org/10.18485/aeletters.2019.4.4.2

\author{
Aleksandar Skulić ${ }^{1 *}$, Blaža Stojanović ${ }^{1}$, Saša Radosavljević ${ }^{1}$, Sandra Veličković ${ }^{1}$ \\ ${ }^{1}$ University of Kragujevac, Faculty of Engineering, Sestre Janjić 6, 34000 Kragujevac, Serbia
}

\begin{abstract}
:
This paper deals with the analysis of impact of various factors on power loss and efficiency of worm gearing. Factors that significantly affect the power losses are, principally, types of materials of meshed gears and geometry of worm pair, type and viscosity of lubricating oils, input rotational speed, worm shape, loading, temperature, etc. Results of experimental tests of worm gearing efficiency are also presented in the paper. Tests were conducted according to planned experiment schedule on specialized device AT200, where single-stage worm gearboxes with transmission ratio $i=18$ has been used. During the test stage, oils of different viscosities (ISOVG 220, ISOVG 460 and ISOVG 680) have been used and their impact on efficiency was monitored. The values of efficiency level are determined at different input rotational speeds (circumferential velocity) and output torques (loads).
\end{abstract}

\section{INTRODUCTION}

Worm gearing as hyperboloid worm pairs whose axes intersect (most recent at the angle of $90^{\circ}$ ) are characterized by the line contact of the worm and worm gear which is followed by high sliding friction between coupled elements. Relatively high level of sliding causes forming of a large amount of heat and power loss which is accompanied with low level of efficiency of worm gearing. Apart from that in the phase of coupling between the line contact of the worm and worm gear, appropriate normal force is being transmitted and that force leads to significant surface pressures which can cause destruction of the side lines of the teeth during the work because of the pitting. These kind of coupling conditions demand special measures for the finishing quality, selection of the material for the worm pair and particularly for providing of oil film between coupled lines of teeth [1].

\author{
ARTICLE HISTORY \\ Received: 22.09.2019. \\ Accepted: 02.12.2019. \\ Available: 31.12.2019.

\section{KEYWORDS} \\ Efficiency, power losses, \\ worm gearing, materials, \\ oil viscosity
}

Apart from sliding friction in the coupled worm and worm gear, friction occurs in the bearings, between gears and oil, in the seals etc. [2]. The consequences of the friction at the worm gearing are power losses, lower level of efficiency, scuffing and damaging of gearing elements, gearing heating, vibration and noise, shorter period of exploitation etc.

The power losses in worm gearing which are represented over the efficiency, depend on various influential factors. The factors which have significant influence on power losses and efficiency are: types of materials of meshed gears and the geometry of the worm pair, circumferential velocity (input rotational speed), type and the viscosity of lubricating oils, loading, worm shape, temperature etc. [3-5].

Types of materials of meshed gears has great influence on the power losses in the worm gearing. The best tribological characteristics are obtained by combining the worm materials made of hardened (case, improved) steel with ground teeth 
and worm gear made of centrifugal casted tin bronze [5,6]. Worm gears made of aluminum alloys and brass also have good characteristics.

The type and the viscosity of the lubricating oils have significant influence on the efficiency as well. The thickness of oil film has important influence on the occurrence of surface fatigue, the lasting of the contact surfaces and worm pair efficiency. Optimal lubricant is the one that provides less gear scuffing and low working temperatures as well as longer period of worm gearing exploitation [7-9].

Geometrical characteristics and the worm pair type also have important influence on the worm gearing efficiency. Namely, reducing the power loss in the worm gearing can be significantly influenced by correlating the ration of mean diameter and axial distance, higher lead angles and lower transmission ratios $[10,11]$.

When it comes to the selection of the worm pair type, most often are used cylindrical worm pairs which are simple to make and biuld in. Worm pairs type ZA, ZN, ZK and ZI have approximately the same load capacity and power losses and they are similar concerning the oil film between meshed teeth flanks. Worm pairs type ZC are better concerning the lubricating conditions and the shape of the worm pairs, therefore have bigger load capacity and lower power losses [5]. On the other hand, multi-stage worms with the favorable selection of the kinematic ratio, lubrication and constructional concept, can achieve relatively high efficiency.

\section{POWER LOSSES AND EFFICIENCY}

Worm gearing while operating dissipates energy so that at the output shaft it receives power which is less than the input power for the loss size. Overall power losses at the worm gearing are consisted of sliding friction power loss in gear mesh $\mathrm{P}_{\mathrm{GZ}}$, power losses in bearings $\mathrm{P}_{\mathrm{GL}}$, power losses in the idle mode $\mathrm{P}_{\mathrm{GO}}$ and power losses in the seals $P_{G D}$, i.e.:

$$
P_{G}=P_{G Z}+P_{G L}+P_{G O}+P_{G D} .
$$

Overall power losses are divided basically into load-dependent power losses and power losses in the idle mode [12]. Sliding friction power loss in gear mesh and power losses in bearings are involved in both cases. Power losses in the seals as well as the other power losses in worm gearing are not load-dependent [13].
Worm gearing efficiency is a very important parameter of the gearing quality. Overall efficiency, in the case of energy generating worm shaft, is calculated by the following equation:

$$
\eta=\frac{P_{2}}{P_{1}}=\frac{P_{2}}{P_{2}+P_{G}} .
$$

where are: $\mathrm{P}_{1}$ - power on the worm; $\mathrm{P}_{2}$ - power on the worm gear and $\mathrm{P}_{\mathrm{G}}$ - overall power losses.

Calculation of power losses and efficiency of worm gearing can be done using the equations that are shown in the following literature $[1,5,13$ $16]$.

\section{DEVICE FOR THE EFFICIENCY TESTING}

Experimental testings are carried on the AT 200 device which is designed for determination of gearboxes efficiency (Fig.1a). Main parts of the device are electromotor (1), nominal power $0.2 \mathrm{~kW}$, which leans over two bearings on the top part of the chassis (2) which allows it to rotate around its horizontal axe. The chassis of the electromotor is connected to the main frame of the device using the appropriate tightening levers so it can be moved along the metal guides. The input torque can be determined by multiplying the value of the balancing force that is read off on the dynamometer (3) and the length of the lever (4) which is set in the horizontal position (Fig.1b).

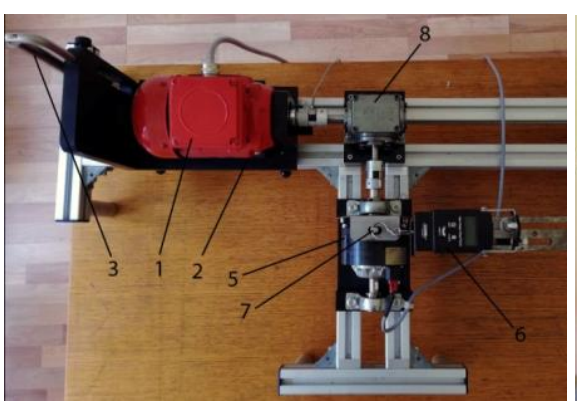

(a)

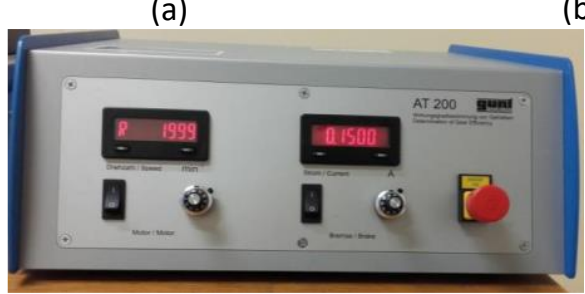

(c)

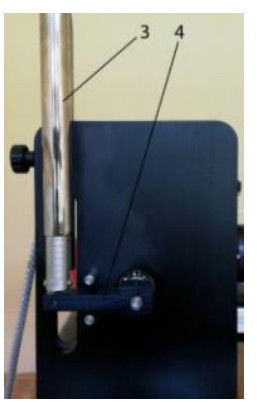

(b)
Fig. 1. Device AT 200 (a), dynamometer with the lever (b) and the control unit (c)

The braking torque on the output shaft of the worm reducer is changed by the magnetic brake (5). The brake is mounted to the two-part chassis which allows connecting the brake to the various 
gearboxes. The braking torque is calculated by multiplying the braking force, which is read off on the dynamometer (6), and the distance between the center of the brake and the place on the little shaft (7) where the dynamometer is connected. Adjusting the motor rotational speed and the braking force is performed by the control unit (Fig.1c). The sensor detecting the number of revolution is located on the output shaft of the electromotor and its values are changed by the potentiometer on the control unit. The values of the braking force are also changed by the control unit when we change the current intensity $(0-0.3$ A) whereby maximum braking torque of $10 \mathrm{Nm}$ can be achieved.

Single-stage worm reducer (8), which is specially constructed for that purpose, is used for the experimental testing. The reducer construction is such that allows simple installation and deinstallation of the worm pair, bearings and other parts. The basic data about tested worm pair are shown in the Table 1.

Table 1. Basic characteristics of the tested worm pair

\begin{tabular}{|c|c|}
\hline Geometrical size & Values \\
\hline Number of teeth $\mathrm{z}_{1} / \mathrm{z}_{2}$ & $1 / 18$ \\
\hline Central distance $a[\mathrm{~mm}]$ & 31 \\
\hline Transmission ratio $i$ & 18 \\
\hline Module $m[\mathrm{~mm}]$ & 2 \\
\hline Worm material & $42 \mathrm{CrMo} 4$ \\
\hline Wheel material & CuSn14 \\
\hline
\end{tabular}

The reducer is mounted on the special chassis which is set up on the device frame with the appropriate tightening levers. The connecting of the reducer to the electromotor shaft and the magnetic brake is achieved by the claw shaped couplings.

\section{EXPERIMENTAL TESTINGS RESULTS}

The values of the efficiency, during experimental testing, are determined in different operation conditions, i.e. with different input rotational speed and loads (output torque). Mineral oils with different viscosity are used for the testing and their influence on the worm reducer efficiency is monitored.

Diagram of a dependency of the overall efficiency and output torque $T_{2}$ obtained by means of experimental values for the input rotational speed $\mathrm{n}_{1}=1500 \mathrm{~min}^{-1}$ and $220 \mathrm{~mm}^{2} / \mathrm{s}$ oil viscosity, is shown in Fig.2.
Changing the current intensity on the magnetic brake caused the values of the output torque to move in the range of $T_{2}=1.8-5.2 \mathrm{Nm}$. The values of the input power $P_{1}$ and output power $P_{2}$ are determined at the same time. The values of overall efficiency are calculated by the equation (2) and they changed within the interval $\eta=0.48-0.57$. The trend of the output torque change flow lines shows that with the increase of the load the overall worm reducer efficiency increases as well.

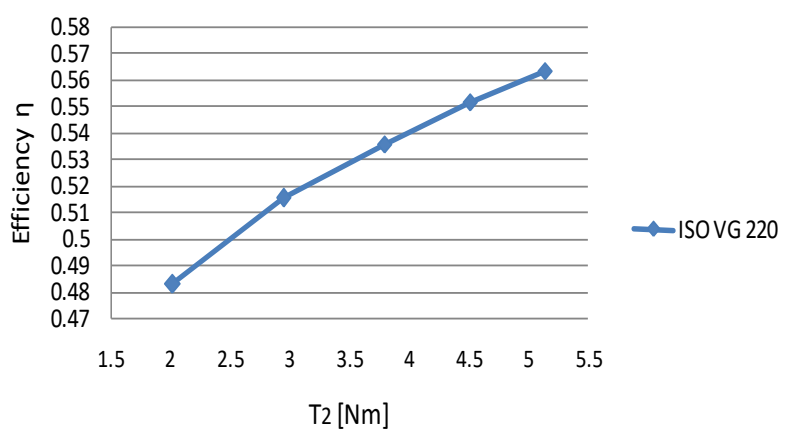

Fig. 2. Overall worm reducer efficiency obtained by means of experiment for the input rotational speed $n_{1}=$ $1500 \mathrm{~min}^{-1}$ and different output torque values $\mathrm{T}_{2} \mathrm{Nm}$

Lubrication oil viscosity has significant influence on the worm reducer efficiency. Mineral oils with different viscosity made by Modriča refinery (ISOVG 220, ISOVG 460 and ISOVG 680) were used during the experimental testings and their influence on worm reducer efficiency was monitored. The intensity of the current on the brake changed in the interval $0.1-0.2 \mathrm{~A}$, with a change step of 0.025 A (five levels of loads). Overall experiment lasted 8 hours per oil (the first level of loads lasting for 2 hours and 1.5 hours for each of the next levels). Figures 3 and 4 show measured values of efficiency for oils with different viscosity with input rotational speed $n_{1}=$ $2000 \mathrm{~min}^{-1}$ and $\mathrm{n}_{1}=2500 \mathrm{~min}^{-1}$.

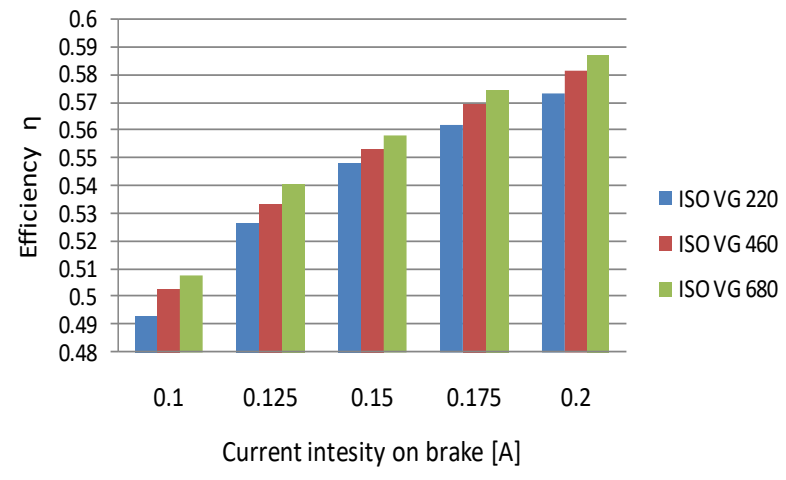

Fig. 3. Values of efficiency for oils with different viscosity with input rotational speed $\mathrm{n}_{1}=2000 \mathrm{~min}^{-1}$

Figures 3 and 4 show that higher values of efficiency were obtained using oils with higher 
viscosity for all levels of load. The difference between the viscosity of the used oils was between $1 \%$ and $2 \%$. Using higher viscosity oils lead to higher losses in idle mode but generally lead to lower power losses of worm gearing due to better forming of oil film between the contact surfaces of gear teeth, especially when the level of load is higher.

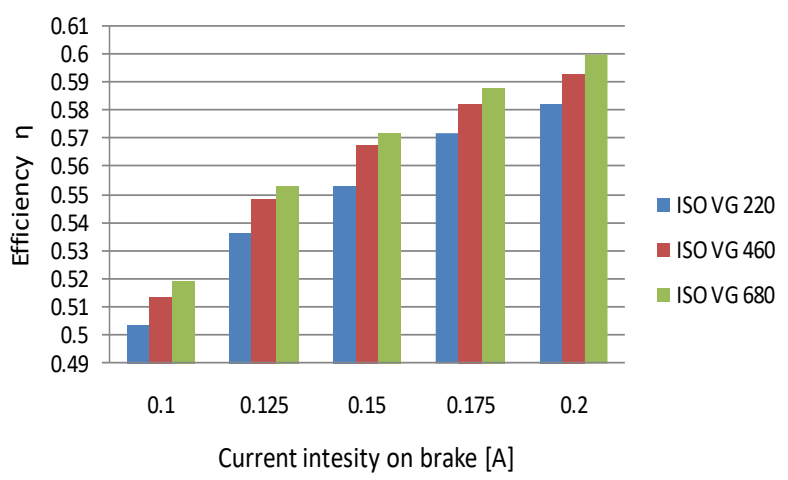

Fig. 4. Values of efficiency for oils with different viscosity with input rotational speed $\mathrm{n}_{1}=2500 \mathrm{~min}^{-1}$

On the other hand, higher values of efficiency were measured with higher input rotational speed $\mathrm{n}_{1}$. For example, for the oil with viscosity ISO VG 460 and the rotational speed $\mathrm{n}_{1}=2000 \mathrm{~min}^{-1}$. the values of the efficiency changed in the interval $\eta=$ $0.50-0.58$, whilst those values were a bit higher for the rotational speed $n_{1}=2500 \mathrm{~min}^{-1}$ and the same oil viscosity $(\eta=0.51-0.59)$ considering all the levels of load. With the increase of the circumferential velocity it is easier to form the oil film between the contact surfaces of gear teeth which creates conditions for total (hydrodynamical) lubrication, therefore the efficiency increases as well.

\section{CONCLUSION}

Worm gearing power losses, which are shown over the efficiency, may vary in wide limits and that depends on the various influential factors such as: types of materials of meshed gears and the geometry of the worm pair, circumferential velocity, type and the viscosity of lubricating oils, loading, worm shape, temperature etc.

As the absolute efficiency cannot exist even in the theoretical considerations, it is possible to reduce power losses in the worm gearing by using different design solutions and varying of the influential factors, therefore the efficiency can be higher.

This is shown by experimental testings where the influence of the circumferential velocity (input rotational speed $n_{1}$ ), oil viscosity and loads on worm reducer efficiency were monitored, which leads us to these conclusions:

- The values of the efficiency changed in the interval $\eta=0.48-0.57$ for the input rotational speed $\mathrm{n}_{1}=1500 \mathrm{~min}^{-1}$ and oil viscosity of 220 $\mathrm{mm}^{2} / \mathrm{s}$. Diagram of a dependency of the overall efficiency and output torque $T_{2}$ (Fig.2) shows that higher values of efficiency were obtained with higher output torque i.e. loads.

- With higher circumferential velocity it is easier to form oil film between the contact surfaces of gear teeth, therefore the measured values of the efficiency were higher. The values of the efficiency changed in the interval $\eta=0.50-$ 0.58 for the oil with the viscosity ISO VG 460 and the rotational speed $\mathrm{n}_{1}=2000 \mathrm{~min}^{-1}$, and with increasing of the circumferential velocity $\left(n_{1}=2500 \mathrm{~min}^{-1}\right)$ those values were a bit higher and they changed in the interval $\eta=0.51-$ 0.59 . The increasing of the efficiency with the change of the circumferential velocity was achieved also in the case when oils ISO VG 220 and ISO VG 680 were used.

- Using higher viscosity oils leads to higher efficiency. Diagram of a dependency of the efficiency and the oil viscosity shows that the difference between the viscosity of the used oils was between $1 \%$ and $2 \%$. Using higher viscosity oils can provide a forming of the oil film (that is thick enough) between the contact surfaces of gear teeth, especially at the higher temperature and loads.

\section{REFERENCES}

[1] V. Nikolić, Mechanical elements. Faculty of Mechanical Engineering, Kragujevac, 2004.

[2] N. Marjanović, Optimization of gear power transmitters-Monograph, Faculty of Mechanical Engineering, Kragujevac, 2007.

[3] A. Skulić, D. Krsmanović, S. Radosavljević, L. Ivanović, B. Stojanović, Power losses of worm gear pairs. Acta Technica Corvininesis-Bulletin of Engineering, 10 (3), 2017: 39-45.

[4] S. Radosavljević, B. Stojanović, A. Skulić Determination of power losses in worm gear reducer, The $10^{\text {th }}$ International Conference on Machine and Industrial Design in Mechanical Engineering (KOD 2018), $6^{\text {th }}-8^{\text {th }} J u n e, 2018$, Novi Sad, Serbia, pp.1-8.

[5] V. Miltenović, Mechanical elements - form, calculation, implementation, Faculty of Mechanical Engineering, Niš, 2009. 
[6] V. Fontanari, M. Benedetti, G. Straffelini, C. Girardi, L. Giordanino, Tribological behavior of the bronzesteel pair for worm gearing. Wear 302 (1), 2013: 1520-1527.

https://doi.org/10.1016/i.wear.2013.01.058

[7] E.M. Mautner, W. Sigmund, J.P. Stemplinger, K. Stahl, Efficiency of worm gearboxes, Proceedings of the Institution of Mechanical Engineers, Part C. Journal of Mechanical Engineering Science, 230 (16), 2016: 2952-2956. https://doi.org/10.1177/0954406215602286

[8] B. Stojanović, S. Radosavljević, S. Velicković, S. Miladinović, M. Bukvić, The influence of lubricant viscosity of the efficiency of worm gear reducer, 8th International scientific conference Research and development of mechanical elements and systems (IRMES 2017), $7^{\text {th }}-9^{\text {th }}$ September, 2017, Trebinje, B\&H, pp.219-224

[9] A. Rac, Lubricants and lubrication of machines, Faculty of Mechanical Engineering, Belgrade, 2007.

[10] R.G. Budynas, J.K. Nisbett, Mechanical Engineering Design, Tenth edition, McGraw-Hill Education, New York, 2015.

[11] Dubbel: Taschenbuch für den Maschinenbau. Springer Verlag, Edition 23, Berlin Heidelberg, Germany, 2011.
[12] A. Asonja, E. Desnica, Reliability of agriculture universal joint shafts based on temperature measuring in universal joint bearing assemblies. Spanish Journal of Agricultural Research, 13 (1), 2015: e02-001.

http://dx.doi.org/10.5424/sjar/2015131-6371

[13] DIN 3996: Tragfähigkeitsberechnung von ZylinderSchneckengetrieben mit sich rechtwinklig kreuzenden Achsen. Deutsches Institut für Normung e. V., Beuth Verlag, 2012.

[14] B. Magyar, B. Sauer, Calculation of the Efficiency of Worm Gear Drives, Power Transmission Engineering, 2015: 52-56.

[15] AGMA Design manual for cylindrical wormgearing. ANSI/AGMA Standard 6022-C93. Reaffirmed, 2008.

[16] SKF General Catalogue 6000 EN, SKF; November, 2005.

An expanded abstract of this research was presented at " 9 th International Scientific Conference IRMES 2019", September 5-7, 2019, Kragujevac, Serbia. 